\title{
High expression of proenkephalin is associated with favorable outcomes in patients with gastrointestinal stromal tumors
}

This article was published in the following Dove Press journal: Cancer Management and Research

\author{
Defeng Tang ${ }^{1,2}$ \\ Tianlong Lin' \\ Yangyang Wang' \\ Hui Cao' \\ 'Department of Gastrointestinal Surgery, \\ Renji Hospital, Shanghai Jiao Tong \\ University School of Medicine, Shanghai \\ 200 I27, People's Republic of China; \\ ${ }^{2}$ Department of General Surgery, \\ Tongren Hospital, Shanghai Jiao Tong \\ University School of Medicine, Shanghai \\ 200336, People's Republic of China
}

Purpose: The aim of this study was to elucidate the prognostic value of proenkephalin $(P E N K)$ in gastrointestinal stromal tumors (GISTs).

Patients and methods: We collected data on 268 eligible postoperative patients diagnosed with GIST between January 1, 2002, and December 31, 2011. PENK expression was detected in GIST tissues classified using the United States National Institutes of Health (NIH) risk classification system. The associations between high PENK expression and the clinicopathological characteristics were assessed. Overall survival (OS) and recurrence-free survival (RFS) were estimated by Kaplan-Meier analysis, and the log-rank test was used to compare the differences between groups. Univariate and multivariate Cox regression analyses were conducted to assess the prognostic value of PENK in GIST patients.

Results: High PENK expression was more common in the low- and intermediate-risk GIST groups compared with the high-risk group $(P<0.05)$. Additionally, PENK expression was associated with tumor size, mitosis count per 50 high-power fields, and tumor rupture $(P<0.05)$. Kaplan-Meier analysis revealed that high PENK expression was associated with superior OS and RFS, while low PENK expression was associated with worse OS and RFS. Furthermore, PENK was shown to be an independent predictor of OS and RFS in the overall population (for OS, hazard ratio [HR], 1.596, 95\% confidence interval [CI], 1.006-2.914, $P<0.001$; for RFS, HR, 1.910, 95\% CI, 0.977-3.089, $P<0.001$ ).

Conclusion: PENK expression in GIST is closely associated with NIH risk grade and prognosis, indicating that PENK may act as a tumor suppressor and may serve as a new biomarker for predicting prognosis in postoperative GIST patients.

Keywords: PENK, GIST, prognosis
Correspondence: Hui Cao Department of Gastrointestinal Surgery, Renji Hospital, Shanghai Jiao Tong University School of Medicine, 1630 Dongfang Road, Shanghai 200127, People's Republic of China

Tel +862168383731

Fax +862158394262

Email caohuisjtu@I63.com

\section{Introduction}

Gastrointestinal stromal tumor (GIST) is the most common mesenchymal malignancy in the digestive tract. ${ }^{1}$ Most GISTs have gain-of-function mutations in the $c$ $K I T$ or platelet-derived growth factor receptor alpha (PDGFRA) genes, which both encode receptor tyrosine kinases (RTKs); this results in constitutive $R T K$ activation, which drives tumorigenesis and determines the response to imatinib treatment. ${ }^{2-4}$ However, $10-15 \%$ of GISTs do not harbor $c-K I T$ or PDGFRA mutations; these GISTs may have neurofibromin $1(N F 1)$, B-Raf proto-oncogene $(B R A F)$, or succinate dehydrogenase $(S D H)$ gene mutations. ${ }^{5,6}$ A wealth of published studies suggest that $c$-KIT mutations occur at the early stages of GIST development. These findings indicate that $c$-KIT activation is a key point in most GISTs and possibly an initiating 
tumorigenic event. ${ }^{7-9}$ Clearly, the $c-K I T$ or PDGFRA mutations do not represent all the important factors involved in the continuing development of GISTs. As a promising therapeutic agent, imatinib is generally not curative, although it is quite effective at stabilizing GIST progression. ${ }^{10}$ Even after long-term imatinib treatment, most patients are left with a substantial tumor burden, showing that significant numbers of GIST cells can survive imatinib treatment. ${ }^{11}$ Moreover, imatinib withdrawal in such patients results in rapid recurrence, which inevitably leads to the requirement for lifelong imatinib therapy. ${ }^{12}$ Therefore, it is critical to find new agents or strategies related to non-kinase biochemical pathways that may help regulate classical RTK-driven signaling to resolve the current problems.

Neurotransmitters are widely found in both the gastrointestinal system and the nervous system. Such neurotransmitters are so-called brain-gut peptides. Previous research on gastrointestinal neoplasms have highlighted that these brain-gut peptides contribute to gastrointestinal tumor pathogenesis and can be used as biomarkers for diagnosis and prognosis, including metastasis prediction, in patients with gastrointestinal neoplasms. ${ }^{13-16}$ One neurotransmitter that has recently attracted great interest is proenkephalin (PENK), which is abnormally expressed in several cancers and is associated with cancer suppression pathways. ${ }^{17,18} \mathrm{In}$ gastrointestinal carcinomas, the enzymatic product of PENK, opioid growth factor (OGF), has been demonstrated to be a tumor suppressor, and the OGF-OGF receptor (OGFR) axis plays an important role in the process of tumor growth inhibition. ${ }^{19-21}$ However, to the best of our knowledge, no studies have been conducted on pathogenic effects of PENK or its clinical relevance in GIST.

In the present study, we made the first attempt to fill this gap by investigating the contribution of PENK in GIST. In particular, we set out to study its relevance as a prognostic biomarker. Accordingly, we analyzed PENK mRNA and protein expression levels in GIST tissues and validated our results in a large-scale GIST patient cohort. We believe that PENK is a promising biomarker for GIST prognosis and may be a potential agent for GIST treatment.

\section{Materials and methods}

\section{Patients and follow-up}

A retrospective analysis was performed on 268 patients with GIST admitted to the Department of Gastrointestinal Surgery, Renji Hospital, Shanghai, China, from January 1, 2002, to
December 31, 2011. The inclusion criteria were as follows: 1) definite pathologic diagnosis of GIST involving c-KIT (CD117)-positive immunohistochemistry (IHC) staining results; 2) radical surgery conducted; 3) clinicopathologic and follow-up data available; and 4) patient consent and approval of the Regional Ethical Committee of Renji Hospital. The exclusion criteria were as follows: 1) primary GIST cases with any other malignant tumors; 2) chemotherapy/radiotherapy before surgery; and 3) lack of patient consent. Clinicopathologic parameters, comprising age, gender, tumor site, tumor size $(\mathrm{cm})$, mitosis count per 50 high-power fields (HPF), tumor rupture, mutation type, and imatinib use, were obtained from Renji Hospital records. According to the modified National Institutes of Health (NIH) risk classification system, ${ }^{22}$ patients were divided into very low-, low-, intermediate-, and high-risk categories. The very low- and low-risk categories were combined to create a new low-risk category. All the patients involved in our research accepted regular follow-up until January 1, 2017, according to the National Comprehensive Cancer Network (NCCN) GIST guidelines. ${ }^{23}$ Overall survival (OS) was defined as the time from the date of surgery to death or the last follow-up time. Recurrence-free survival (RFS) was defined as the time from the date of surgery to first diagnosis of tumor recurrence or last observation. All the patients enrolled in this study signed informed consent forms. Ethical approval (no. 2016033) was obtained from the Regional Ethical Committee, Renji Hospital, School of Medicine, Shanghai Jiao Tong University, Shanghai, P.R. China.

\section{Tissue microarray construction and gene mutation sequencing}

Tissue microarrays were designed and manufactured by Suzhou Xinxin Biotechnology Co., Suzhou, China. ${ }^{24}$ Gene mutation analysis was carried out by Sanger sequencing. Exons 9, 11, and 13 of the $c$-KIT gene and exons 12 and 18 of the PDGFRA gene were analyzed.

\section{IHC staining and scoring}

IHC staining was performed according to the guidelines previously reported by our laboratory. ${ }^{24} \mathrm{~A}$ monoclonal mouse anti-PENK antibody (1:400, ab150346, Abcam, USA) was used. Semi-quantitative analysis of PENK staining was conducted. The staining intensity was scored as negative (0), weak positive (1), positive (2), or strong positive (3). The percentage of positive cells was scored as $<5 \%$ (0), $5-24 \%$ (1), $25-50 \%$ (2), or $>50 \%$ (3). The IHC 
scores (ranging from 0 to 9) were calculated by multiplying these two values. IHC scores $\geq 4$ were defined as high PENK expression (positive), and scores $<4$ were defined as low PENK expression (negative). All IHC scores were independently assessed by two pathologists with no access to the clinical information.

\section{Total RNA extraction and quantitative real-time (qRT)-PCR}

Fresh GIST tissue specimens stored in liquid nitrogen from 36 GIST patients with low risk (comprising the very low- and low-risk groups based on the NIH risk classification system), intermediate risk, and high risk (12 cases with each) were randomly selected. The total RNA of the 36 tissue specimens was extracted using Trizol reagent (Takara, Dalian, China) following the manufacturer's instructions. The cDNAs of the 36 tissues were used as templates for qRT-PCR using the SYBR-Green method. qRT-PCR was conducted using a StepOne ${ }^{\mathrm{TM}}$ Real-Time PCR System (Applied Biosystems, Foster City, CA, USA). Glyceraldehyde phosphate dehydrogenase (GAPDH) was used as an internal control. The $2^{-\Delta \mathrm{Ct}}$ method was used to quantify the relative $P E N K$ expression levels. The forward and reverse $P E N K$ primer sequences were 5'-TGCAGGTTTCCCAAATTTTC-3' and 5'-GTGCAGCTACCGCCTAGTG-3', respectively.

\section{Western blotting (WB)}

The WB analysis was performed according to guidelines previously reported by our laboratory. ${ }^{24}$ Seven tissue specimens from the abovementioned 36 tissue specimens were randomly selected (three low-risk, two intermediate-risk, and three high-risk tissue specimens) The following primary antibodies were used for WB: polyclonal goat anti-PENK (1:2000, ab77273, Abcam) and monoclonal rabbit anti-GAPDH (1:5000, ab181602, Abcam).

\section{Statistical analyses}

Statistical analyses were performed using SPSS 10.0 software (SPSS Inc., Chicago, IL, USA). The associations of high PENK expression with clinicopathological characteristics were assessed using chi square tests and one-way analysis of variance (ANOVA). The Kaplan-Meier method was used to assess OS and RFS and the log-rank test was used to compare survival. Univariate and multivariate Cox proportional hazards regression analyses were conducted. $P$-values involved in the analysis were 2-sided, and those $<0.05$ were considered statistically significant.

\section{Results}

\section{Baseline characteristics of patients}

A total of 268 patients with GIST (143 males and 125 females) were analyzed in this study. The patients' clinicopathological characteristics are presented in Table 1. The median age at diagnosis was 58 years, with a range of 23-87 years; 130 patients $(48.5 \%)$ were aged $<58$ years. According to the NIH risk classification system (based on tumor size, site, and rupture, and mitotic phase), 12 patients (4.5\%) were classified as having very low risk, 91 (34\%) as having low risk, 43 (16\%) as having intermediate risk, and $122(45.5 \%)$ as having high risk. Of the 114 patients (42.5\%) who had undergone gene mutation examination, 89 had a kit11 mutation, 10 had a kit9 mutation, 6 had a PDGFRA mutation (5 of which had a D842V mutation), and the remaining 9 were wild type for the KIT/PDGFRA exons analyzed. Only 55 patients (20.5\%) with intermediate/high NIH risk grades received postoperative imatinib mesylate therapy. The follow-up duration (from the day of surgery) ranged from 3 to 149 months (median, 79.5 months), and 11 patients (4.1\%) were lost to follow-up.

\section{Expression levels of PENK mRNA and protein in GISTs}

PENK expression in GIST tissues was detected by qRT-PCR and WB assays among 36 GIST patients with low risk (comprising the very low- and low-risk groups based on the NIH risk classification system), intermediate risk, and high risk (12 cases with each level of risk). The qRT-PCR results indicated that with increasing NIH risk grade, the relative PENK mRNA expression level $\left(2^{-\triangle \mathrm{Ct}}\right)$ decreased from the low-risk group to the intermediate-risk group and to the highrisk group $(P=0.008)$. Paired comparisons between the groups showed that the low- and intermediate-risk groups had significantly higher PENK mRNA expression levels than the high-risk group $(P=0.002)$ (Figure $2 \mathrm{~A})$; however, there was no significant difference between the low- and intermediate-risk groups $(P=0.166)$. WB analyses of randomly selected cases from the 36 GIST tissue specimens (three lowrisk, two intermediate-risk, and three high-risk tissue specimens) exhibited the same results (Figure 2B, 2C). These data indicated that PENK was more highly expressed in the low-/ intermediate-risk groups than in the high-risk group.

\section{PENK protein expression level in GISTs is closely associated with $\mathrm{NIH}$ risk grade}

Based on the above findings, we subsequently conducted a large-scale tissue microarray analysis to detect the expression 
Table I Clinicopathological characteristics of 268 GIST patients

\begin{tabular}{|c|c|}
\hline Clinicopathological characteristic & Patients, n (\%) \\
\hline \multicolumn{2}{|l|}{$\mathrm{Age}^{\mathrm{a}}$ (year) } \\
\hline$\leq 58$ & $130(48.5 \%)$ \\
\hline$>58$ & $138(5 \mid .5 \%)$ \\
\hline \multicolumn{2}{|l|}{ Gender } \\
\hline Male & $143(53.4 \%)$ \\
\hline Female & $125(\%)$ \\
\hline \multicolumn{2}{|l|}{ Tumor site } \\
\hline Stomach & $150(56 \%)$ \\
\hline Small bowel & $84(31.3 \%)$ \\
\hline Colon & $9(3.4 \%)$ \\
\hline Other & $25(9.3 \%)$ \\
\hline \multicolumn{2}{|l|}{ Tumor size $(\mathrm{cm})$} \\
\hline$\leq 2$ & $13(4.9 \%)$ \\
\hline$>2 \& \leq 5$ & $101(37.7 \%)$ \\
\hline$>5 \& \leq 10$ & $97(36.2 \%)$ \\
\hline$>10$ & $57(21.2 \%)$ \\
\hline \multicolumn{2}{|l|}{ Mitosis count per $50 \mathrm{HPFs}$} \\
\hline$\leq 5$ & $18 \mid(67.5 \%)$ \\
\hline$>5 \& \leq 10$ & $45(16.8 \%)$ \\
\hline$>10$ & $42(15.7 \%)$ \\
\hline \multicolumn{2}{|l|}{ Modified NIH risk grade } \\
\hline Very low & $12(4.5 \%)$ \\
\hline Low & $91(34 \%)$ \\
\hline Intermediate & $43(16 \%)$ \\
\hline High & $122(45.5 \%)$ \\
\hline \multicolumn{2}{|l|}{ Tumor rupture } \\
\hline Yes & $4 \mathrm{I}(15.3 \%)$ \\
\hline No & $227(74.7 \%)$ \\
\hline \multicolumn{2}{|l|}{ Tumor mutation type } \\
\hline KIT exon II & $89(33.2 \%)$ \\
\hline KIT exon 9 & $10(3.7 \%)$ \\
\hline PDGFRA & $6(2.3 \%)$ \\
\hline PDGFRA D842V & $5(1.9 \%)$ \\
\hline KIT/PDGFRA wild type & $9(3.4 \%)$ \\
\hline Not analyzed & $154(57.5 \%)$ \\
\hline \multicolumn{2}{|l|}{ Imatinib treatment } \\
\hline Yes & $55(20.5 \%)$ \\
\hline No & $213(79.5 \%)$ \\
\hline \multicolumn{2}{|l|}{ Follow-up duration, months } \\
\hline Median (range) & $79.5(3-149)$ \\
\hline
\end{tabular}

Notes: ${ }^{2}$ The median age of the enrolled GIST patients was 58 , and the range was 23 to 87.

Abbreviations: GIST, gastrointestinal stromal tumor; HPF, high-power fields; $\mathrm{NIH}$, National Institutes of Health.

of PENK in 268 GIST specimens. As shown in Figure 1, in GIST tissues, positive PENK expression was localized to the cell cytoplasm and easily observed in low/intermediate-risk tissues but hardly detected in high-risk tissues. The IHC staining results showed that 93 cases (34.7\%) had high PENK expression and 175 cases (65.3\%) had low PENK expression. Only 12 cases $(9.8 \%, 12 / 122)$ in the high-risk group had high PENK expression. The associations between PENK expression and the clinicopathological parameters are shown in Table 2. We found that high PENK expression was significantly more common in the patients with low-/intermediate-risk grade, smaller tumor size $(\leq 10 \mathrm{~cm})$, or lower mitosis count than in the patients with high-risk grade, larger tumor size $(>10 \mathrm{~cm})$, or higher mitosis count $(P<0.01)$, respectively. We also found that the proportion with high PENK expression significantly differed between GIST patients with tumor rupture (51.2\%) and those with tumor integrity $(31.7 \% ; P=0.016)$. However, PENK expression was not associated with age, gender, or tumor site.

\section{High PENK expression predicts improved survival rate in GIST patients}

We further investigated the associations of PENK expression with OS and RFS in GIST patients using the Kaplan-Meier method and Cox's proportional hazards regression. The Kaplan-Meier analysis revealed that the OS and RFS in the low-/intermediate-risk group (5-year OS rate, 97.3\%, 145/149 (Figure 3A); 5-year RFS rate, 95.3\%, 142/149 (Figure 3B)) were remarkably superior to those in the high-risk group (5-year OS rate, 77.3\%, 92/119 (Figure 3A); 5-year RFS rate, $53.8 \%, 64 / 119$ (Figure 3B)) $(P=0.001)$. However, there were no significant differences between the low- and intermediate-risk groups in OS or RFS ( $P=0.320$ and $P=0.281$ respectively) (Figure $3 \mathrm{~A}$ and $\mathrm{B}$ ) according to the NIH risk grade classification. The Kaplan-Meier analysis also revealed that the OS in the high PENK expression group (5-year OS rate, $93.5 \%, 87 / 93$ ) was remarkably superior to that in the low PENK expression group (5-year OS rate, 82.3\%, 144/175) $(P=0.034)$ (Figure 3C). Similarly, the RFS in the high PENK expression group (5-year RFS rate, 95.7\%, 89/93) was significantly higher than that in the low PENK expression group (5year RFS rate, $81.7 \%, 143 / 175)(P=0.033)$ (Figure 3D). Furthermore, the univariate and multivariate Cox regression analyses showed that high PENK expression was significantly associated with favorable survival rate (OS and RFS) in GIST patients (for OS, hazard ratio (HR), 1.596, 95\% confidence interval (CI), 1.006-2.914, $P<0.001$ (Table 3); for RFS, HR, $1.910,95 \%$ CI, $0.977-3.089, P<0.001$ ) (Table 4)). Age, gender, and tumor site were not associated with OS or RFS in the multivariate models, while tumor size, tumor rupture, and 

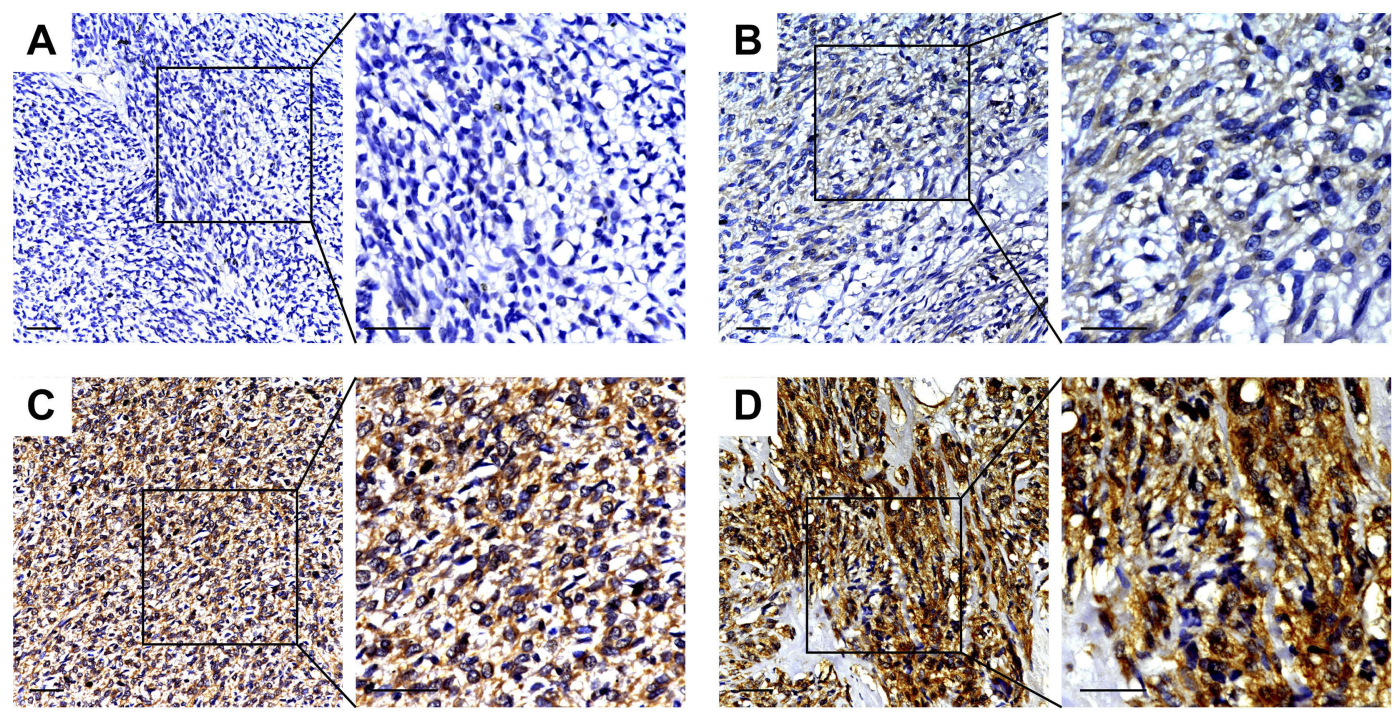

Figure I PENK expression detected in GIST tissues by immunohistochemical staining.

Notes: (A) Negative, (B) weak positive, (C) moderate, and (D) strong positive PENK staining in GIST tissues.

Abbreviations: GIST, gastrointestinal stromal tumor; PENK, proenkephalin.

A

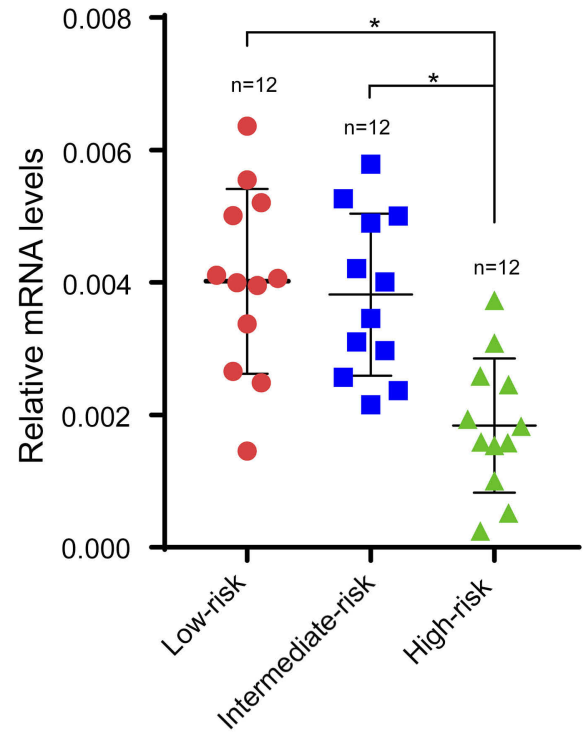

C

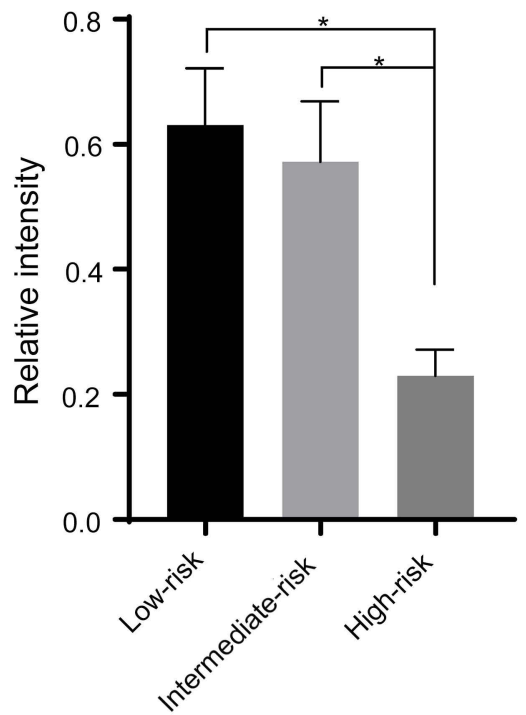

B

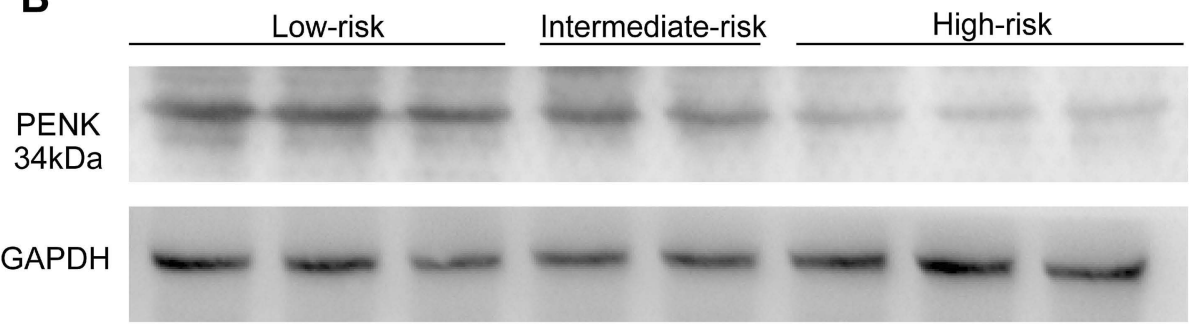

Figure 2 PENK expression in GIST tissues detected by qRT-PCR and WB.

Notes: $(A)$ Relative mRNA expression levels of $P E N K$ in the low- and intermediate-risk groups were significantly higher than that in the high-risk group $(P=0.004$ and $P=0.012$, respectively). (B, C) WB analysis showed that $P E N K$ protein expression levels in the low- and intermediate-risk groups were higher than that in the high-risk group $(P=0.002$ and $P=0.008$, respectively). However, there was no significant difference between the low- and intermediate-risk groups $(P=0.166)$. GAPDH was included as a loading control. Abbreviations: GAPDH, glyceraldehyde phosphate dehydrogenase; GIST, gastrointestinal stromal tumor; PENK, proenkephalin; qRT-PCR, quantitative real-time polymerase chain reaction; WB, Western blotting. 
Table 2 Clinicopathological characteristics of 268 GIST patients grouped by PENK expression

\begin{tabular}{|c|c|c|c|c|}
\hline \multirow{2}{*}{$\begin{array}{l}\text { Clinicopathological } \\
\text { characteristic }\end{array}$} & \multirow[t]{2}{*}{$\mathbf{n}$} & \multicolumn{2}{|l|}{ PENK } & \multirow[t]{2}{*}{$P$-value } \\
\hline & & $\begin{array}{l}\text { Negative } \\
\text { (\%) }\end{array}$ & $\begin{array}{l}\text { Positive } \\
\text { (\%) }\end{array}$ & \\
\hline Age (year) & & & & 0.588 \\
\hline$\leq 58$ & 130 & $87(32.5)$ & $43(16.0)$ & \\
\hline$>58$ & 138 & $88(32.8)$ & $50(18.7)$ & \\
\hline Gender & & & & 0.676 \\
\hline Male & 143 & $95(35.4)$ & $48(17.9)$ & \\
\hline Female & 125 & $80(29.9)$ & $45(16.8)$ & \\
\hline Tumor site & & & & 0.106 \\
\hline Stomach & 150 & $91(34.0)$ & $59(22.0)$ & \\
\hline Small bowel & 84 & $58(21.6)$ & $26(9.7)$ & \\
\hline Colon & 9 & $6(2.2)$ & $3(1.1)$ & \\
\hline Other & 25 & $16(6.0)$ & $9(3.3)$ & \\
\hline Tumor size $(\mathrm{cm})$ & & & & $0.00 I^{* *}$ \\
\hline$\leq 10$ & 211 & $127(47.4)$ & $84(31.3)$ & \\
\hline$>10$ & 57 & $48(17.9)$ & $9(3.3)$ & \\
\hline Mitosis count per $50 \mathrm{HPFs}$ & & & & $<0.001 * *$ \\
\hline$\leq 5$ & $|8|$ & $96(35.8)$ & $85(31.7)$ & \\
\hline$>5$ & 87 & $79(29.5)$ & $8(3.0)$ & \\
\hline Tumor rupture & & & & $0.026 *$ \\
\hline Yes & 41 & $33(12.3)$ & $8(3.0)$ & \\
\hline No & 227 & $142(53.0)$ & $85(31.7)$ & \\
\hline Modified NIH risk grade & & & & $<0.00 I^{* *}$ \\
\hline Very low or low & 103 & $38(14.2)$ & $65(24.3)$ & \\
\hline Intermediate & 43 & $23(8.6)$ & $20(7.5)$ & \\
\hline High & 122 & $110(41.0)$ & $12(4.5)$ & \\
\hline
\end{tabular}

Notes: Pearson chi square tests and one-way ANOVA were used to compare the associations between PENK expression and the clinicopathological variables. $* P<0.05 ; * * P<0.01$.

Abbreviations: GIST, gastrointestinal stromal tumor; HPF, high-power field; $\mathrm{NIH}$, National Institutes of Health; PENK, proenkephalin.

mitosis count were, not surprisingly, associated with both OS and RFS $(P<0.01)$ (Table 3, Table 4).

\section{Discussion}

Most GISTs harbor gain-of-function $c$-KIT or PDGFRA mutations, which is critical for GIST growth and maintenance. ${ }^{2}$ Targeted therapies against $c-K I T$ or PDGFRA mutations have greatly improved the survival of GIST patients. However, acquired resistance eventually occurs in almost all GIST patients during treatment. ${ }^{3,4}$ In addition, approximately $10-15 \%$ of GISTs do not harbor $c$ KIT or PDGFRA mutations. ${ }^{5,6}$ Thus, there is a need to find new biomarkers and treatment strategies to fill the gap. PENK, which has a molecular weight of $34 \mathrm{kDa}$ and is located on human chromosome $8 \mathrm{q} 12.1$, may be a candidate. It is mainly localized to the cell matrix, and is also found in the cell membrane, nucleus, and mitochondria. It also acts as a neurotransmitter, encoding a preproprotein that is proteolytically processed to generate multiple kinds of protein products. ${ }^{25,26}$ PENK-derived peptides act as neurotransmitters, neuromodulators, and neurohormones; exhibit opioid activity; participate in responses to stress and pain; and contribute to appetite and sleep regulation. ${ }^{27}$ In addition, the PENK gene is expressed in several nonneuronal tissues, including endocrine glands such as the adrenal medulla, immune system cells, and embryonal skin mesenchymal cells. ${ }^{28-30}$ Recently, PENK and PENK-derived peptides have been reported to be associated with the regulation of gastric, head and neck, and pancreatic cancers. $^{20,31,32}$ However, the expression and clinical significance of $P E N K$ in GIST have not been previously reported.

In this study, to elucidate the clinical significance of $P E N K$ in GIST, we detected the PENK mRNA level in 36 GIST tissue specimens with different NIH risk grades by qRT-PCR, and the PENK protein level in seven tumor specimens by WB analysis. Both the qRT-PCR and WB results showed that PENK was highly expressed in low-/intermediate-risk tumors compared to high-risk tumors, which suggested that $P E N K$ might act as a tumor growth suppressor. Additionally, the IHC results of a large-scale sample of GIST tissues showed that high PENK expression was observed in $60.4 \%$ of low-/intermediate-risk tumors, but in only $9.8 \%$ of high-risk tumors. Thus, the IHC results were consistent with the qRT-PCR and WB results, further indicating that PENK might act as a negative factor during the progression of GIST. In addition, the data revealed that PENK expression was negatively associated with tumor size, tumor rupture, and mitosis count, which suggested that PENK expression might be associated with slow GIST progression and may act as a tumor progression inhibition factor. However, there are few related studies focused on the associations between $P E N K$ knockdown and tumor progression in different types of human neoplasms. In a future study, we will investigate these associations. Many studies have reported the antitumor effect of OGF (a PENK-derived peptide) in a variety of cancers. McLaughlin et al reported that OGF inhibits the progression of human squamous cell carcinoma of the head and neck transplanted into nude mice. ${ }^{20}$ Zagon et al also found that human pancreatic cancer cell growth is tonically inhibited by OGF. ${ }^{31}$ Further investigation by Cheng et al confirmed these results in pancreatic cancer. ${ }^{33}$ The function 
A

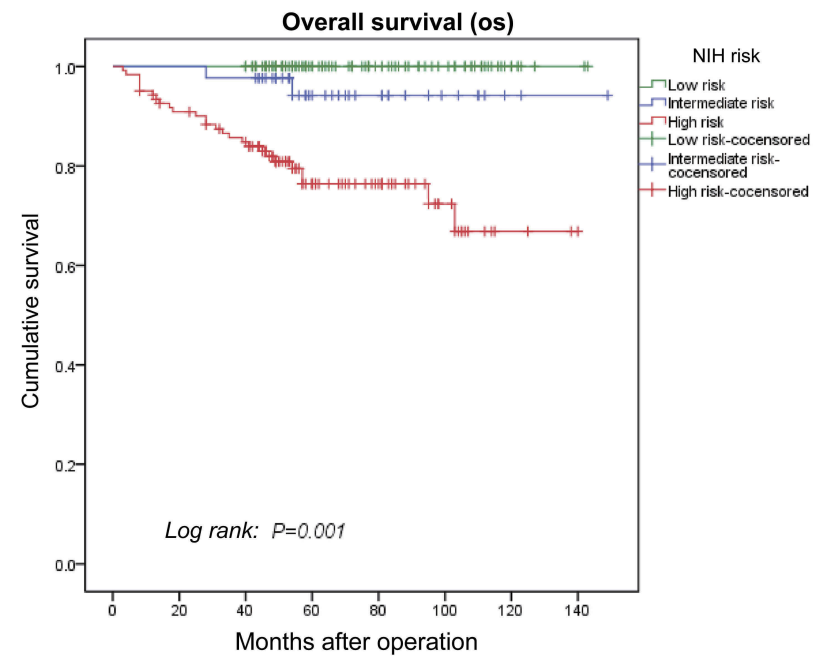

B

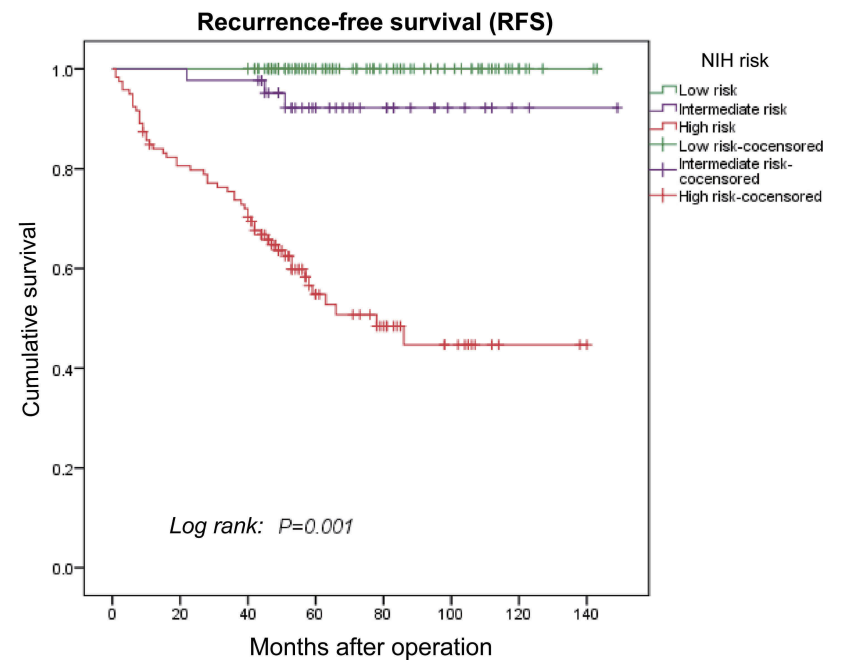

C

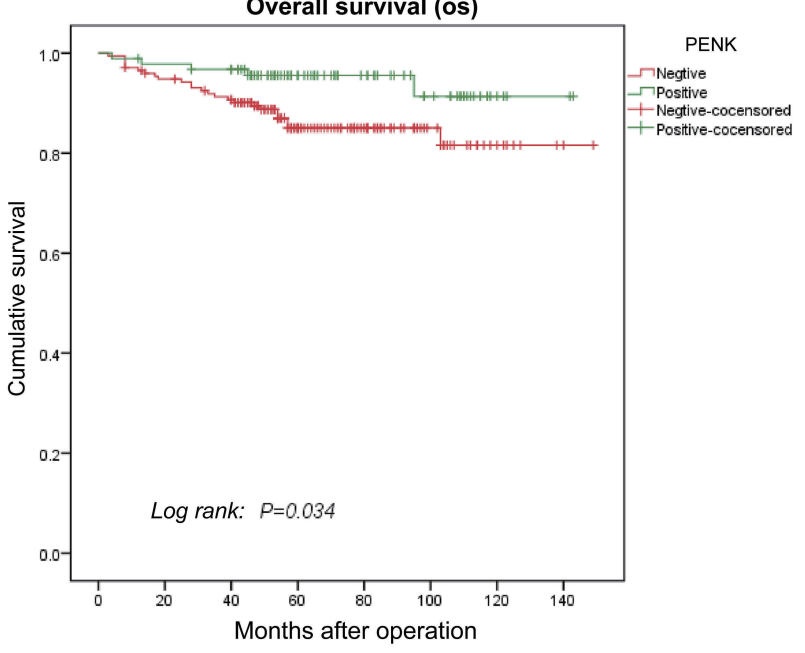

D

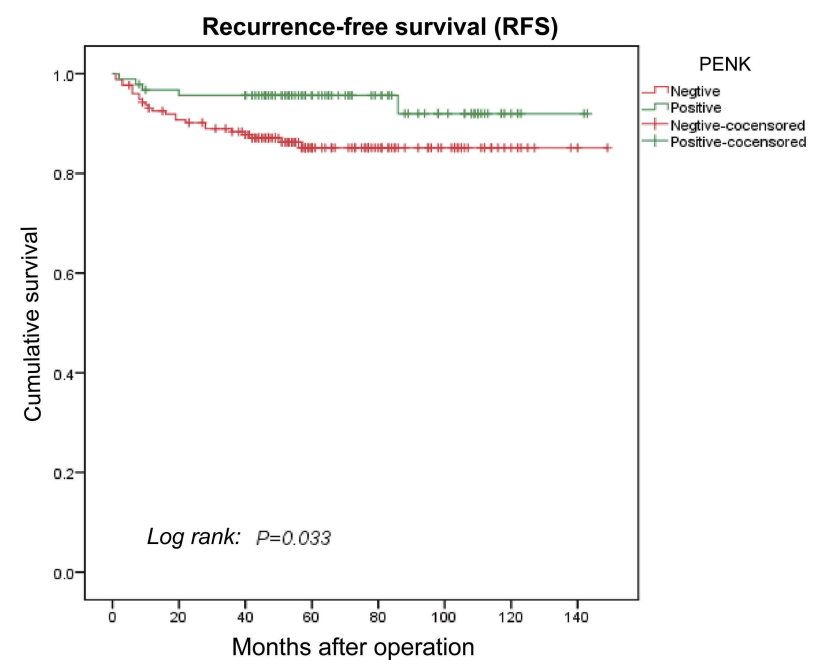

Figure 3 Prognostic value of PENK expression in 268 GISTs was assessed using the Kaplan-Meier method and the log-rank test.

Notes: Comparisons of $(\mathbf{A})$ OS $(P=0.00 \mathrm{I})$ and $(\mathbf{B})$ RFS $(P=0.00 \mathrm{I})$ among low-, intermediate-, and high-risk NIH grades. Comparisons of $(\mathbf{C})$ OS $(P=0.034)$ and RFS $(P=0.033)$ between PENK-negative and PENK-positive groups.

Abbreviations: GIST, gastrointestinal stromal tumor; NIH, National Institutes of Health; OS, overall survival; PENK, proenkephalin; RFS, recurrence-free survival.

Table 3 Univariate and multivariate analyses of predictors of OS in 268 GIST patients

\begin{tabular}{|c|c|c|c|c|c|c|}
\hline \multirow[t]{2}{*}{ Variable } & \multicolumn{3}{|c|}{ Univariate } & \multicolumn{3}{|c|}{ Multivariate } \\
\hline & HR & $95 \% \mathrm{Cl}$ & $P$-value & HR & $95 \% \mathrm{Cl}$ & $P$-value \\
\hline Age $(\leq 58,>58)$ & 1.409 & $0.698-2.536$ & 0.312 & 1.465 & $0.68 \mathrm{I}-2.735$ & 0.310 \\
\hline Gender (male, female) & 0.963 & $0.476-1.998$ & $0.039 *$ & 1.201 & $0.458-2.340$ & 0.112 \\
\hline Tumor site (stomach, other) & 1.740 & $1.087-2.715$ & $0.035^{*}$ & 3.309 & $1.901-5.213$ & 0.271 \\
\hline Tumor size $(\leq 10 \mathrm{~cm},>10 \mathrm{~cm})$ & 3.297 & $2.298-4.830$ & $0.001 * *$ & 3.167 & $1.428-5.116$ & $<0.00 I^{* *}$ \\
\hline Mitosis count $(\leq 5 / 50 \mathrm{HPFs},>5 / 50 \mathrm{HPFs})$ & 3.615 & $2.866-5.981$ & $0.000 * *$ & 4.527 & $2.270-7.158$ & $<0.00 I^{* *}$ \\
\hline Tumor rupture (no, yes) & 3.226 & $2.259-5.672$ & $0.038 *$ & 8.210 & $4.614-13.992$ & $0.048 *$ \\
\hline PENK (positive, negative) & 1.460 & $1.300-1.897$ & $0.000 * *$ & 1.596 & $1.006-2.914$ & $<0.001 * *$ \\
\hline
\end{tabular}

Notes: $* P<0.05 ; * * P<0.01$. $95 \% \mathrm{Cl}, 95 \%$ confidence interval.

Abbreviations: GIST, gastrointestinal stromal tumor; HPF, high-power field; HR, hazard ratio; OS, overall survival; PENK, proenkephalin. 
Table 4 Univariate and multivariate analyses of predictors of RFS in 268 GIST patients

\begin{tabular}{|c|c|c|c|c|c|c|}
\hline \multirow[t]{2}{*}{ Variable } & \multicolumn{3}{|c|}{ Univariate } & \multicolumn{3}{|c|}{ Multivariate } \\
\hline & HR & $95 \% \mathrm{Cl}$ & $P$-value & HR & $95 \% \mathrm{Cl}$ & $P$-value \\
\hline Age $(\leq 58,>58)$ & 1.612 & $0.769-2.755$ & 0.410 & 1.827 & $1.012-3.136$ & 0.536 \\
\hline Gender (male, female) & 1.157 & $0.598-2.362$ & 0.056 & 1.670 & $0.458-3.610$ & 0.326 \\
\hline Tumor site (stomach, other) & 2.078 & $0.827-3.610$ & $0.042^{*}$ & 4.005 & I.744-7.035 & 0.620 \\
\hline Tumor size $(\leq 10 \mathrm{~cm},>10 \mathrm{~cm})$ & 4.863 & $3.210-7.853$ & $0.006 * *$ & 4.278 & $2.029-7.080$ & $0.001 *$ \\
\hline Mitosis count $(\leq 5 / 50 \mathrm{HPFs},>5 / 50 \mathrm{HPFs})$ & 4.211 & $3.900-6.899$ & $0.000 * *$ & 5.109 & $3.664-8.002$ & $<0.00 I^{* *}$ \\
\hline Tumor rupture (no, yes) & 4.138 & $1.186-8.002$ & $0.022 *$ & 10.104 & $7.014-13.87 \mid$ & $0.037^{*}$ \\
\hline PENK (positive, negative) & 1.956 & $1.515-2.897$ & $0.000 * *$ & 1.910 & $0.977-3.089$ & $<0.00 I^{* *}$ \\
\hline
\end{tabular}

Notes: $* P<0.05 ; * * P<0.01 .95 \% \mathrm{Cl}, 95 \%$ confidence interval.

Abbreviations: GIST, gastrointestinal stromal tumor; HPF, high-power field; HR, hazard ratio; PENK, proenkephalin; RFS, recurrence-free survival.

of OGF involves reversible, non-cytotoxic, and non-apoptotic induction, independent of the cell status regarding differentiation, migration, invasion, or adhesion, and this occurs at physiological concentrations, including in a variety of poorly differentiated and well-differentiated human cell lines. ${ }^{34,35}$ The function of OGF in tumors is to target DNA synthesis and block the G0/G1 phase. ${ }^{25,36,37}$ Administration of OGF in vitro has a strong antitumor effect on tumor progression, slowing tumor growth and reducing tumor size. ${ }^{34,38}$ Additionally, the combination of biotherapy with OGF has been shown to lead to increased antitumor effects compared to chemotherapy alone. ${ }^{35,38}$ Therefore the mechanism of OGF in GIST deserves further investigation.

The Kaplan-Meier analysis revealed that PENK expression was closely associated with the OS and RFS of GIST patients. GIST patients with low PENK expression had worse OS and RFS than those with high expression. Therefore, we concluded that PENK is a predictor of favorable survival rate (OS and RFS) in GIST patients. Univariate and multivariate Cox regression analyses also showed that high PENK expression was significantly associated with favorable survival rate (OS or RFS) in GIST patients. As a result, PENK was shown to be an independent predictor in the overall GIST population. In addition to mitotic rate, tumor size, and localization, which are used for the NIH risk grade classification, PENK expression may also play an important role in the risk grade classification of GISTs. The great clinical value of PENK in predicting the recurrence risk of postoperative GIST patients may contribute to improving clinical therapeutic effects.

\section{Conclusion}

In this retrospective study, we found that high PENK expression was associated with better OS and RFS in GIST patients and that PENK was an independent predictor of OS and RFS in the overall GIST patient population. These results indicate that PENK may be negatively associated with GIST progression. Detection of the PENK expression level in postoperative patients might therefore improve therapeutic decision making for these patients. However, the molecular mechanism of PENK in GIST deserves further investigation.

\section{Acknowledgments}

The authors appreciated the medical records staff at the Department of Gastrointestinal Surgery, Renji Hospital, Shanghai Jiao Tong University School of Medicine, who provided the detailed patient records, and all the researchers who supported our study.

\section{Disclosure}

The authors declare no conflicts of interest in this work.

\section{References}

1. Rubin BP, Heinrich MC, Corless CL. Gastrointestinal stromal tumor. Lancet. 2007;369(9574):1731-1741. doi:10.1016/S01406736(07)60780-6

2. Heinrich MC, Corless CL, Demetri GD, et al. Kinase mutations and imatinib response in patients with metastatic gastrointestinal stromal tumor. J Clin Oncol. 2003;21(23):4342-4349. doi:10.1200/ JCO.2003.04.190

3. Heinrich MC, Corless CL, Duensing A, et al. PDGFRA activating mutations in gastrointestinal stromal tumors. Science. 2003;299 (5607):708-710. doi:10.1126/science.1079666

4. Joensuu H, Rutkowski P, Nishida T, et al. KIT and PDGFRA mutations and the risk of GI stromal tumor recurrence. J Clin Oncol. 2015;33 (6):634-642. doi:10.1200/JCO.2014.57.4970

5. Gasparotto D, Rossi S, Polano M, et al. Quadruple-negative GIST is a sentinel for unrecognized neurofibromatosis type 1 syndrome. Clin Cancer Res. 2017;23(1):273-282. doi:10.1158/1078-0432. CCR-16-0152

6. Rossi S, Sbaraglia M, Dell'Orto MC, et al. Concomitant KIT/BRAF and PDGFRA/BRAF mutations are rare events in gastrointestinal stromal tumors. Oncotarget. 2016;7(21):30109-30118. doi:10.18632/oncota rget. 8768 
7. Heinrich MC, Owzar K, Corless CL, et al. Correlation of kinase genotype and clinical outcome in the North American intergroup phase III trial of imatinib mesylate for treatment of advanced gastrointestinal stromal tumor: CALGB 150105 study by cancer and leukemia group B and southwest oncology group. J Clin Oncol. 2008;26 (11):5360-5367. doi:10.1200/JCO.2007.15.2777

8. Corless CL, McGreevey L, Haley A, et al. KIT mutations are common in incidental gastrointestinal stromal tumors one centimeter or less in size. Am J Pathol. 2002;160(5):1567-1572. doi:10.1016/ S0002-9440(10)61103-0

9. Corless CL, Barnett CM, Heinrich MC. Gastrointestinal stromal tumors: origin and molecular oncology. Nat Rev Cancer. 2011;11 (19):865-878. doi:10.1038/nrc3143

10. Blanke CD, Demetri GD, von Mehren M, et al. Long-term results from a randomized phase II trial of standard- versus higher-dose imatinib mesylate for patients with unresectable or metastatic gastrointestinal stromal tumors expressing KIT. J Clin Oncol. 2008;26 (4):620-625. doi:10.1200/JCO.2007.15.2777

11. Blay JY, Le Cesne A, Ray-Coquard I, et al. Prospective multicentric randomized phase III study of imatinib in patients with advanced gastrointestinal stromal tumors comparing interruption versus continuation of treatment beyond 1 year: the French sarcoma group. J Clin Oncol. 2007;25(9):1107-1113. doi:10.1200/JCO.2006.09.0183

12. Heinrich MC, Corless CL, Blanke CD, et al. Molecular correlates of imatinib resistance in gastrointestinal stromal tumors. J Clin Oncol. 2006;24(29):4764-4774. doi:10.1200/JCO.2006.06.2265

13. Okada N, Kubota A, Imamura T, et al. Evaluation of cholecystokinin, gastrin, CCK-A receptor, and CCK-B/gastrin receptor gene expressions in gastric cancer. Cancer Lett. 1996;106(2):257-262. doi:10.1016/03043835(96)04325-X

14. Phillips CM, Zatarain JR, Nicholls ME, et al. Upregulation of cystathionine- $\beta$-synthase in colonic epithelia reprograms metabolism and promotes carcinogenesis. Cancer Res. 2017;77(21):5741-5754. doi:10.1158/0008-5472.CAN-16-3480

15. Renz BW, Takahashi R, Tanaka T, et al. $\beta 2$ adrenergic-neurotrophin feedforward loop promotes pancreatic cancer. Cancer Cell. 2018;33 (1):75-90. doi:10.1016/j.ccell.2017.11.007

16. Padickakudy R, Pereyra D, Offensperger F, et al. Bivalent role of intraplatelet serotonin in liver regeneration and tumor recurrence in humans J Hepatol. 2017;67(6):1243-1252. doi:10.1016/j.jhep.2017.08.009

17. Roperch JP, Incitti R, Forbin S, et al. Aberrant methylation of NPY, PENK, and WIF1 as a promising marker for blood-based diagnosis of colorectal cancer. BMC Cancer. 2013;13:566. doi:10.1186/1471-2407-13-566

18. Foy JP, Pickering CR, Papadimitrakopoulou VA, et al. New DNA methylation markers and global DNA hypomethylation are associated with oral cancer development. Cancer Prev Res (Phila). 2015;8 (11):1027-1035. doi:10.1158/1940-6207.CAPR-14-0179

19. Zagon IS, Donahue R, McLaughlin PJ. Targeting the opioid growth factor: opioid growth factor receptor axis for treatment of human ovarian cancer. Exp Biol Med (Maywood). 2013;238(5):579-587. doi: $10.1177 / 1535370213488483$

20. McLaughlin PJ, Stucki JK, Zagon IS. Modulation of the opioid growth factor ([Met(5)]-enkephalin)-opioid growth factor receptor axis: novel therapies for squamous cell carcinoma of the head and neck. Head Neck. 2012;34(4):513-519. doi:10.1002/hed.21759

21. Zagon IS, Porterfield NK, McLaughlin PJ. Opioid growth factoropioid growth factor receptor axis inhibits proliferation of triple negative breast cancer. Exp Biol Med (Maywood). 2013;238(6):589599. doi: $10.1177 / 1535370213489492$

22. Joensuu H. Risk stratification of patients diagnosed with gastrointestinal stromal tumor. Hum Pathol. 2008;39(10):1411-1419. doi:10.1016/j.humpath.2008.06.025
23. von Mehren M, Randall RL, Benjamin RS, et al. Soft tissue sarcoma, version 2.2018, NCCN clinical practice guidelines in oncology. J Natl Compr Canc Netw. 2018;16(5):536-563. doi:10.6004/ jnccn.2018.0025

24. Ma MZ, Zhuang C, Yang X, et al. CTHRC1 acts as a prognostic factor and promotes invasiveness of gastrointestinal stromal tumors by activating Wnt/PCP-Rho signaling. Neoplasia. 2014;16(3):265278. doi:10.1016/j.neo.2014.03.001

25. Zagon IS, Wu Y, McLaughlin PJ. The opioid growth factor, [Met5]enkephalin, and the zeta opioid receptor are present in human and mouse skin and tonically act to inhibit DNA synthesis in the epidermis. J Invest Dermatol. 1996;106(3):490-497. doi:10.1111/15231747.ep12343712

26. Nissen JB, Kragballe K. Enkephalins modulate differentiation of normal human keratinocytes in vitro. Exp Dermatol. 1997;6(5):222229. doi:10.1111/exd.1997.6.issue-5

27. Le Merrer J, Becker JA, Befort K, et al. Reward processing by the opioid system in the brain. Physiol Rev. 2009;89(4):1379-1412. doi:10.1152/physrev.00005.2009

28. Kuis W, Villiger PM, Leser HG, Lotz M. Differential processing of proenkephalin-A by human peripheral blood monocytes and $\mathrm{T}$ lymphocytes. J Clin Invest. 1991;88(3):817-824. doi:10.1172/ JCI115382

29. Rosen H, Krichevsky A, Polakiewicz RD, et al. Developmental regulation of proenkephalin gene expression in osteoblasts. Mol Endocrinol. 1995;9(11):1621-1631. doi:10.1210/mend.9.6.8592511

30. Behar O, Ovadia H, Polakiewicz RD, et al. Lipopolysaccharide induces proenkephalin gene expression in rat lymph nodes and adrenal glands. Endocrinology. 1994;134(1):475-478. doi:10.1210/ endo.134.6.8194472

31. Zagon IS, Smith JP, McLaughlin PJ. Human pancreatic cancer cell proliferation in tissue culture is tonically inhibited by opioid growth factor. Int J Oncol. 1999;14(15):577-584.

32. Suzuki M, Chiwaki F, Sawada Y, et al. Peripheral opioid antagonist enhances the effect of anti-tumor drug by blocking a cell growthsuppressive pathway in vivo. PLoS One. 2015;10(4):12-22. doi:10.1371/journal.pone.0123407

33. Cheng F, McLaughlin PJ, Verderame MF, Zagon IS. The OGF-OGFr axis utilizes the p21 pathway to restrict progression of human pancreatic cancer. Mol Cancer. 2008;7(8):5-16. doi:10.1186/1476-45987-5

34. McLaughlin PJ, Stack BC, Braine KM, et al. Opioid growth factor inhibition of a human squamous cell carcinoma of the head and neck in nude mice: dependency on the route of administration. Int J Oncol. 2004;24(1):227-232.

35. McLaughlin PJ, Jaglowski JR, Verderame MF, et al. Enhanced growth inhibition of squamous cell carcinoma of the head and neck by combination therapy of paclitaxel and opioid growth factor. Int $J$ Oncol. 2005;26(3):809-816.

36. Zagon IS, Wu Y, McLaughlin PJ. Opioid growth factor inhibits DNA synthesis in mouse tongue epithelium in a circadian rhythm-dependent manner. Am J Physiol. 1994;267(3 Pt 2):R645-52.

37. Zagon IS, Roesener CD, Verderame MF, et al. Opioid growth factor regulates the cell cycle of human neoplasias. Int J Oncol. 2000;17 (5):1053-1061.

38. Jaglowski JR, Zagon IS, Stack BC, et al. Opioid growth factor enhances tumor growth inhibition and increases the survival of paclitaxel-treated mice with squamous cell carcinoma of the head and neck. Cancer Chemother Pharmacol. 2005;56(1):97-104. doi:10.1007/s00280-005-1000-9 


\section{Publish your work in this journal}

Cancer Management and Research is an international, peer-reviewed open access journal focusing on cancer research and the optimal use of preventative and integrated treatment interventions to achieve improved outcomes, enhanced survival and quality of life for the cancer patient.
The manuscript management system is completely online and includes a very quick and fair peer-review system, which is all easy to use. Visit http://www.dovepress.com/testimonials.php to read real quotes from published authors. 